\title{
Effect of Seed Size, Suspension Recycling and Substrate Pre-Treatment on the CVD Growth of Diamond Coatings
}

\author{
Awadesh Kumar Mallik ${ }^{*}$, Sandip Bysakh'1, Radhaballabh Bhar ${ }^{2}$, Shlomo Z. Rotter ${ }^{3}$, \\ Joana Catarina Mendes ${ }^{3}$ \\ ${ }^{1}$ CSIR-Central Glass \& Ceramic Research Institute, Kolkata, India \\ ${ }^{2}$ Department of Instrumentation Science, Jadavpur University, Kolkata, India \\ ${ }^{3}$ Instituto de Telecomunicações, Campus Universitário de Santiago, Aveiro, Portugal \\ Email: *amallik@cgcri.res.in
}

Received 2 November 2015; accepted 5 December 2015; published 9 December 2015

Copyright (C) 2015 by authors and Scientific Research Publishing Inc.

This work is licensed under the Creative Commons Attribution International License (CC BY). http://creativecommons.org/licenses/by/4.0/

(c) (7) Open Access

\section{Abstract}

CVD growth of uniform conformal polycrystalline diamond (PCD) coatings over complex three dimensional structures is very important material processing technique. It has been found that the nucleation and subsequent growth period is very critical for successful development of CVD diamond based technologies. There are many methods of enhancing diamond nucleation on foreign substrates-ultrasonic treatment with diamond seed suspension being the best among them. A combination of ultrasonic seeding (US) technique with prior treatment (PT) of the substrate under CVD diamond growth conditions for brief period of time, has found to be very effective in enhancing the diamond nucleation during CVD growth-together they are known as NNP. But successive usage of the same seeding suspension up to ten cycles deteriorates the seeding efficiency. $6^{\text {th }}$ seeding cycle onwards the silicon substrates are barely get covered by diamond crystallites. Five different diamond micron grits were used for seeding the silicon substrates and it is observed that US with the sub-micron particles $(0.25 \mu \mathrm{m})$ is very effective in efficient nucleation of PCD on Si substrates. PT of the substrate somewhat negates the effect of successive use of the same seeding slurry but it is best to avoid recycling of the same seeding suspension using micron size diamond grits.

\section{Keywords}

Microwave Plasma CVD, Seeding, Diamond Micron Grits, Novel Nucleation Process (NNP), Polycrystalline Diamond

\footnotetext{
${ }^{*}$ Corresponding author.
} 


\section{Introduction}

Diamond is one of the most astonishing materials on earth. Not only in terms of aesthetic significance, which has wondered human beings for ages, but also for its technological superiority over others. But it was very recently in the 1950s that man could synthesise diamond inside laboratories. To achieve this, scientists tried to emulate natural environments under which diamond is formed beneath the earth over millions of years in high pressure and high temperature (HPHT) conditions [1]. In 1955, [2] the first artificial diamond crystals were successfully synthesized in laboratory conditions by HPHT method. However, this is very expensive technology in terms of experimental set ups. One has to pour graphite into high pressure (7 - $10 \mathrm{GPa}$ ) anvils and set high enough temperature (1700 - $2000 \mathrm{~K})$ to transform it into diamond phase. Making diamond pieces larger than a few square millimetres is still not possible by this route. In 1949, American researcher William Eversole [3] from Union Carbide Corporation first ever documented low pressure growth of diamond from carbon monoxide gas onto diamond seeds, even before General Electric's HPHT discovery in 1954. Russian researchers independently confirmed results of Eversole in 1969. They used atomic hydrogen which enhanced the growth rate. Spitsyn et al. at the Physical Chemistry Laboratory, RAS, Moscow started growing diamond at low pressure of $10^{-6} \mathrm{~mm}$ of $\mathrm{Hg}$ from $\mathrm{CBr}_{4}$ and $\mathrm{CI}_{4}$ vapors in between $800^{\circ} \mathrm{C}-1000^{\circ} \mathrm{C}$ [4]-[6], since as early as 1956. J. C. Angus of Case Western University pioneered the role of atomic hydrogen in facilitating growth of diamond and removing graphite under chemical vapour deposition (CVD) conditions [7]. But these experiments proceeded very slowly and were looked at like a suspicious process among scientific community [8]. But it is until recently that in the year 1982 a Japanese group at NIRIM successfully developed a very innovative process of synthesising metastable diamond by CVD technique [9] [10]. This so called metastable CVD growth [11] is actually a stable growth of diamond phase with capillary rise in pressure up to 4 GPa under CVD conditions [12] [13]. The challenges of synthesising artificial diamond inside laboratories are still many, like, faster growth rates to grow bigger crystals, purity of the diamond, n-type doping, large area uniformity, process reproducibility etc. The science and technology of CVD diamond [14] [15] is fast developing but is not yet fully commercialised for serving engineering needs, due to technological obstacles in commissioning capable machines/reactors or sustaining economically viable processes. There is further need of thorough fundamental research in understanding the basic science in solving present technological problems. Nucleation and growth have been the most important phenomenon in CVD growth of diamond and they are still debatable processes among scientific community, which motivates authors to carry out the present work. For example it was the general belief among scientists that atomic hydrogen is the most important factor in depositing diamond phase during CVD of diamond but the discovery at Argonne National Laboratory (ANL), using the same reactor which has been utilised in the present work, has shown that diamond can be formed from Ar gas without the presence of atomic hydrogen. Moreover, it was understood that the CVD diamond growth is a metastable process but recently it has been proved that it is formed under stable region of carbon phase diagram. So it is essential to further understand the nucleation and growth mechanisms of CVD diamond [16] for advancement of knowledge in this field, which can add to the existing database.

The general approach of CVD growth of diamond is to seed the foreign substrate with diamond or diamond like particles to initiate nucleation process [17]-[29]. Otherwise diamond phase is very difficult to appear with very low $10^{2}-10^{3}$ nuclei $/ \mathrm{cm}^{2}$ nucleation densities [30]. It is well understood that to synthesise diamond it is essential to start with diamond seeds [31]. The substrate over which diamond growth can happen is also limited to very few materials, which has to meet the stringent conditions of Hume Rothery rules. Silicon is the most widely used substrate material, since it has the similar diamond cubic structure. The lattice parameters are also not very different which allow diamond to grow over silicon. But closed diamond films cannot be deposited on bare silicon substrate and some surface pre-treatment [32] [33] of the silicon substrate prior to CVD growth is required. A custom procedure is the manual scratching of the smooth silicon surface with some abrasive grits, in order to introduce scratches and grooves on the polished surface. These abrasive powders after scratching are also left over inside the microscopic grooves and pits on the substrate surface. If the abrasive powers are composed of diamond grit, the encrusted particles help in nucleation of the sp3 diamond phase under CVD growth environments. But this technique has some limitations: manual scratching does not produce completely random scratches; it rather creates a systematic pattern on the bare silicon substrate depending on the individual who does the scrubbing. Moreover this technique is only applicable for flat surfaces and, as such, complex 3-d structures cannot be abraded manually. These limitations can be overcome if the scratching of the silicon substrate is 
performed with the help of ultra-sonication (US) [34]. By immersing the substrate in an abrasive suspension containing diamond grit and using ultrasounds to agitate it, a random and uniform 3-d substrate seeding, i.e. a surface pattern (US does not produce scratches; if it is observed, then these are due to the mechanical polishing of the Si wafers, and not due to US seeding) with particles embedded inside can be easily obtained on complex 3-d structures. The concentration of the abrasive suspension is supposed to be an important parameter in ultra-sonication method. Since the abrasive particles leave the diamond particles on the polished surface, it is obvious that the concentration of diamond suspensions would determine the density of diamond seeds embedded on the silicon substrate. This density may depend also on the size of the abrasive particle, which can vary from few hundred microns to hundreds of nanometers. Now, it is interesting to note that once an abrasive suspension is prepared, it is not that the suspension is discarded after single use. The same suspension can be reused several times. After each usage, it is expected that the concentration of the suspension is reduced, since some of the abrasive particles get embedded on the substrate surface and also some of them get entrapped inside the scratches and grooves produced on the polished silicon surface. So the concentration and successive usage of slurries can also be important factors in increasing the density of diamond seeds on the substrate. Earlier, researchers used to use diamond grits of few microns sizes but after the advent of detonation nanodiamond (DND) slurries, it became common to seed the silicon substrate [35]-[37] with these slurries. Such techniques of abrasive scratching or ultrasonic seeding could produce nucleation densities from $10^{9}$ to $10^{11}$ per $\mathrm{cm}^{2}$.

Another method of successful nucleation enhancement $\left(10^{11}\right.$ nuclei/ $\left.\mathrm{cm}^{2}\right)$ is to bombard the negatively biased substrate surface [38] [39] with ionised carbon species, which thereby modify the surface structure favourable for diamond nucleation. However, this process is detrimental for device application, since the energetic plasma species can cause deep and wide wounds on substrate surface [40].

Other technique that has been used to enhance the nucleation density is the deposition of a buffer interlayer on the substrate, prior to the US seeding [41]. This practice has reportedly led to nucleation enhancement of NCD and UNCD films [42]-[45] for coating three-dimensional complex structures [46] [47], which has immense technological significance. Buijnsters et al. suggested that metallic nucleation layer might be a solution for developing conformal very thin coatings [48].

Shlomo et al. [49]-[52] have shown in 1990s, that a brief period of pre-treatment (PT) [53] of silicon substrate under CVD diamond growth conditions (GC), before any seeding procedure, would help significantly in nucleation and growth of diamond. The steps [54] [55] that were followed are the followings, 1) to keep the bare substrate inside CVD reactor with conditions similar to diamond growth for 30 minutes (PT), and thereafter 2) to ultrasonically seed the pre-treated substrate (USP) with a diamond abrasive suspension for embedding diamond seeds on the substrate surface. This pre-treatment enhances nucleation density by two orders of magnitude compare to standard US seeding only process. The principle behind nucleation enhancement is such that the $10-15$ nm thin sp3 enriched film [49]) formed during PT supplies an extra amount of carbon during incubation period of diamond nucleation, in addition to the carbon that is provided from the plasma environment. The result is that lateral growth of diamond is promoted immediately after the 3) substrate is exposed to diamond GC. This method also prevents the appearance of the backside crevices which are formed when using typical diamond nucleation processes. The combination of PT, USP and GC steps, are called together novel nucleation process (NNP) [56]-[58], and it can produce $10^{12}$ nuclei/ $/ \mathrm{cm}^{2}$ nucleation density, resulting uniform and conformal nanocrystalline diamond coatings, as thin as $60 \mathrm{~nm}$.

Rotter et al. [49] reported performing NNP under several sets of experimental conditions. PT was conducted on metal coated and uncoated Si substrates using HFCVD, which was followed by identical USP for all the samples. Then again all the samples were exposed to GC except for one sample with microwave plasma CVD (MPCVD) treatment. Rotter used identical CVD parameters for both the PT and GC steps. Sumant et al. [55] reported modified NNP for growing NCD or UNCD. They used MPCVD for both the pre-treatment and growth steps, with an intermediate step of seeding with DND suspension. The only difference between Rotter's earlier work and the work from ANL group was that ANL used higher methane concentration for the pre-treatment step. Lee et al. [53] also reported modified (different parameters for PT and GC steps) NNP with DC arc CVD and HFCVD, and compared the results with "seed" only process. They observed that the pre-treatment deteriorated the nucleation density, contrary to general belief. Whereas, Fahner et al. [59] noticed improvement in nucleation density when they tried to grow boron doped diamond on pre-treated platinum wires.

In all the earlier work, researchers following NNP, have used either HFCVD or low power $2.45 \mathrm{GHz}$ frequency microwave plasma or direct current arc for CVD growth (GC) experiments. Researchers at ANL might 
had used this same DT1800 reactor which is being used in the present work, but there, very thin film UNCD was developed using Ar rich plasma and the same MPCVD process was used for PT as well. Here we report the influence of GC on NNP when $915 \mathrm{MHz}$ MWPCVD reactor was used to grow microcrystalline diamonds over large area in hydrogen rich plasma and when, HFCVD was used for PT. For the work by Sumant et al., the grain size of the diamond crystals was considerably smaller than with hydrogen-rich chemistries and the deposited films are usually referred to as being nanocrystaline diamond (NCD) or ultrananocrystalline diamond (UNCD) films.

\section{Materials \& Methods}

A modified NNP method was followed to prepare the polycrystalline diamond samples.

One silicon wafer was cut into smaller (p-type, $0.5 \mathrm{~mm}$ thick, one side polished and about $25 \mathrm{~mm}^{2}$ ) pieces. Half of the pieces were given PT for 30 minutes in a HFCVD system $\left(1 \% \mathrm{CH}_{4} / \mathrm{H}_{2}\right.$ precursor gas flow, 30 Torr chamber pressure, $600^{\circ} \mathrm{C}$ substrate temperature).

After PT, the Si samples were paired (one with PT, the other without PT) and were successively seeded with diamond grit suspension inside ultrasonic bath (USP). They were prepared to study the effect of suspension saturation. Five different seeding suspensions were prepared (Table 1). Each suspension was used ten times, each time a different pair of silicon samples was seeded, one with PT and the other one without PT. A total number of $2 \times 10 \times 5$ samples were prepared (Figure 1 ).

Table 1. Seeding suspensions.

\begin{tabular}{cc}
\hline Diamond Grit Size $(\mu \mathrm{m})$ & Suspension identification number \\
0.25 & 1 \\
$6-12$ & 2 \\
$10-20$ & 3 \\
$30-40$ & 4 \\
$40-60$ & 5 \\
\hline
\end{tabular}

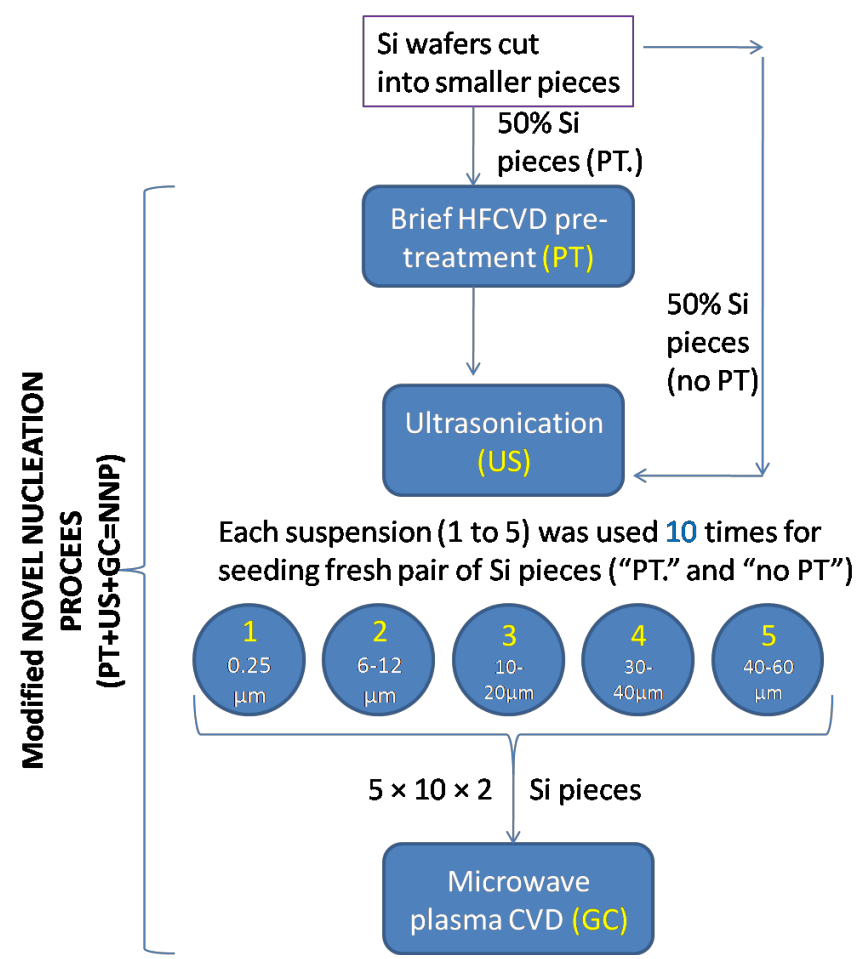

Figure 1. Schematic of the modified novel nucleation process (NNP). 
Each sample is identified by 2 numbers; the first number refers to the particular suspension being used (starting from 1 to 5 , according to Table 1) and the second number refers to the seeding cycle, i.e. the number of times each suspension is being used for seeding (from 1 to 10). Moreover, the samples are marked with a dot (.) which underwent PT. For example a sample with identification number 5-5., has to be considered as a NNP grown polycrystalline diamond (PCD) coated silicon sample, which has been seeded with solution No. 5, the solution was reused for $5^{\text {th }}$ successive time and also the sample was pre-treated under HFCVD growth environment before ultrasonic seeding.

After the first two steps of NNP, (PT or without PT, + USP), the samples were kept inside plastic boxes with proper labelling. Once they were shipped from University of Aveiro, Portugal to CSIR-Central Glass and Ceramic Research Institute, India, the final step of the modified NNP was carried out, i.e., MPCVD diamond growth (GC), using a different reactor, $915 \mathrm{MHz}$ DT1800 (Lambda Technologies Inc. USA).

The smaller pieces of samples from Aveiro were kept over one large $100 \mathrm{~mm}$ diameter $6 \mathrm{~mm}$ thick silicon wafer. Thermal management [60] [61] of plasma heating necessitates usage of such a thick wafer for placing over the thinner silicon sample pieces. Samples were grown using $10 \mathrm{sccm}$ methane gas mixed with $500 \mathrm{sccm}$ of hydrogen and $8 \mathrm{~kW}$ microwave input power with 110Torr pressure. The substrate temperature was maintained at $1050^{\circ} \mathrm{C}$.

The PCD coated experimental samples were then seen under optical microscope (Olympus BX 51, country), electron microscope (Phenom Pro X at $5-15 \mathrm{kV}$ beam energy) for surface structural evaluation. EDAX data were also taken from them to identify the elements present on the PCD growth surface. Laser Raman spectroscopy (STR500, Technos Instruments, originally from Seki Technotron, Japan) was used to identify quality and stress of the as-grown PCD coatings.

\section{Results \& Discussion}

The PCD coated silicon samples were seen under optical microscope, which showed clear crystalline deposition of coatings with the presence of discontinuity among many of them (Figure 2). Figure 2(a) and Figure 2(b) show the different grain sizes observed when the substrate is pre-treated in NNP. 1-3 is the sample without pre-treatment and the sample 1-3. is the one which underwent HFCVD pre-treatment before USP and GC. Figure 2(b) has finer grains compare to Figure 2(a), although both the samples were seeded with $0.25 \mu \mathrm{m}$ diamond grit suspension. The effect of PT on grain size becomes evident when without PT sample 2-2 shows similar (to Figure 2(a)) bigger grains in Figure 2(c). Now, 2-2 was seeded with $6-12 \mu \mathrm{m}$ grit size, whereas sample 3-1 was seeded with bigger $10-20 \mu \mathrm{m}$ grits, but it appears that since none of them were pre-treated, they do not have different grain sizes, but their polycrystals are appearing to be comparable in size. 1-3, 2-2 and 3-1 samples were seeded with gradual increase in grit size (Table 1), which are well reflected in the optical micrographs in Figure 2(a)-(d) with apparent successive bigger PCD crystal sizes. All the samples discussed so far, are seeded with fresh stock (first 5 USP cycles) of diamond suspension, but when the samples like 4-7. and 5-7. ( $7^{\text {th }}$ seeding USP cycle of the same suspension) are observed under optical microscope, it was noticed that there was discontinuous PCD growth over silicon substrates. Discontinuity is more prominent for the sample 5-7. than the sample 4-7. It may be because of their grit size difference. Sizes of the PCD grains are apparently bigger in 5-7. than 4-7., which is again may be because of the bigger grit size used in preparing the substrate. It is to be pointed out that both the samples in Figure 2(e) and Figure 2(f) were pre-treated. It appears that when the old stocks (last 5 USP cycles) of seeding suspension are used even PT cannot become effective to grow fully covered PCD. Moreover, surface of the sample 5-7., although seeded with biggest grit size, appears to be covered with much smaller sized seed particles in Figure 2(f). It can be assumed that the successive use of the ultra-sonication, up to seven times, broke down the macrometer size diamond grit into smaller particle seeds.

So three parameters appear to influence the NNP nucleation and growth characteristics of PCD, and they are abrasive grit size, successive use of same seeding suspension (USP cycles) and substrate pre-treatment (PT). The influences of these three parameters are presented in the following separate sub-sections.

Raman signals (Figure 3) were also taken at 50× magnification with 5 micron laser spot size (inset figures). $514.5 \mathrm{~nm}$ Ar+ ion laser was used for $10 \mathrm{sec}$ of exposure time, successively for 5 times of signal acquisition. The laser spot was focussed on grain (Figure 3(a)), grain boundary (Figure 3(b)), scratch marks (Figure 3(c)) and blackish surface spots (Figure 3(d)) of PCD sample 4-4 (as an example of all the PCD grown), prepared with 30 $40 \mu \mathrm{m}$ grit size suspension used for successive $4^{\text {th }}$ time without PT. It is found that the PCD quality marginally 


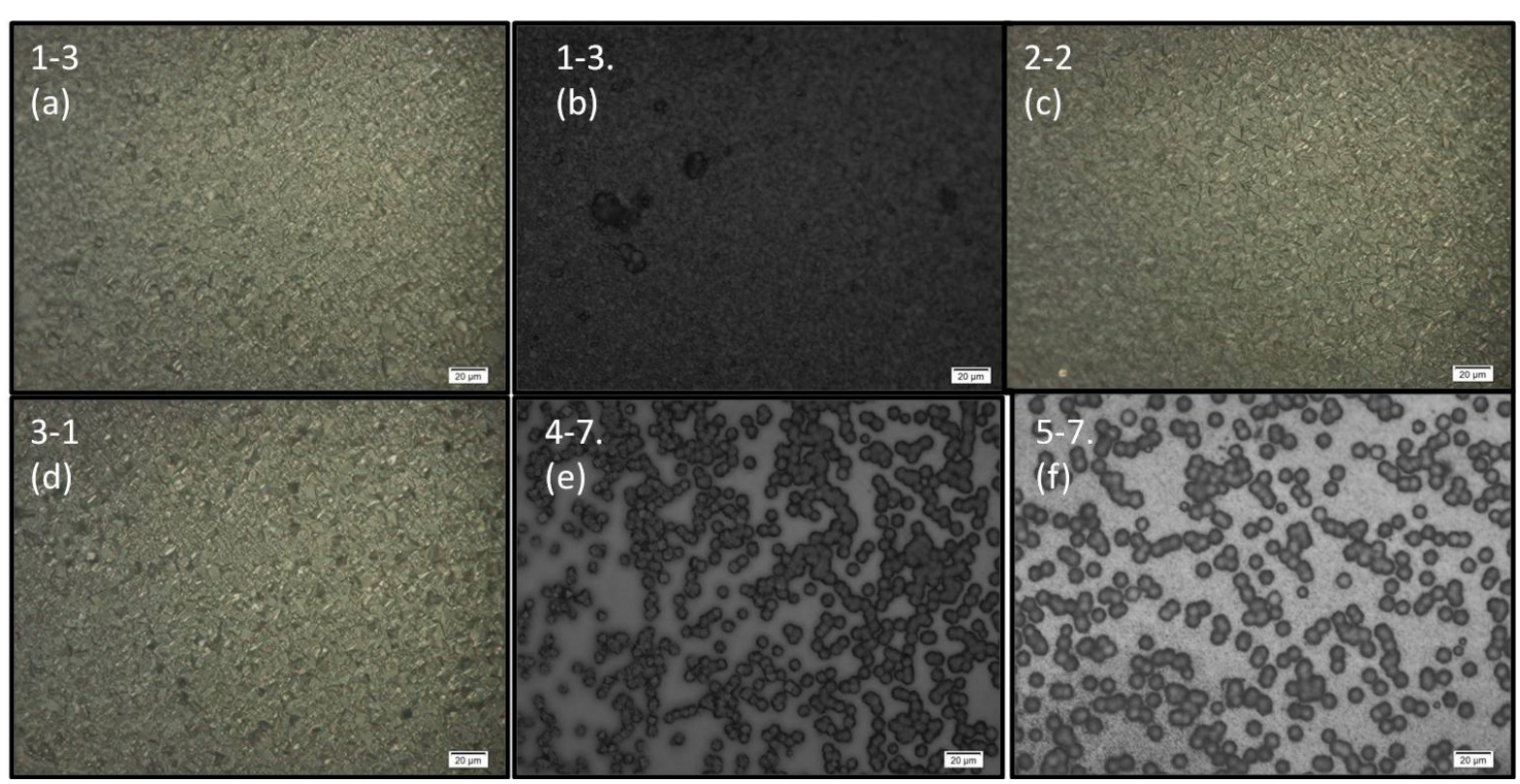

Figure 2. 500× optical microscope images of polycrystalline diamond coatings showing, (a)-(d) full coverage and (e) \& (f) discontinuous growth.
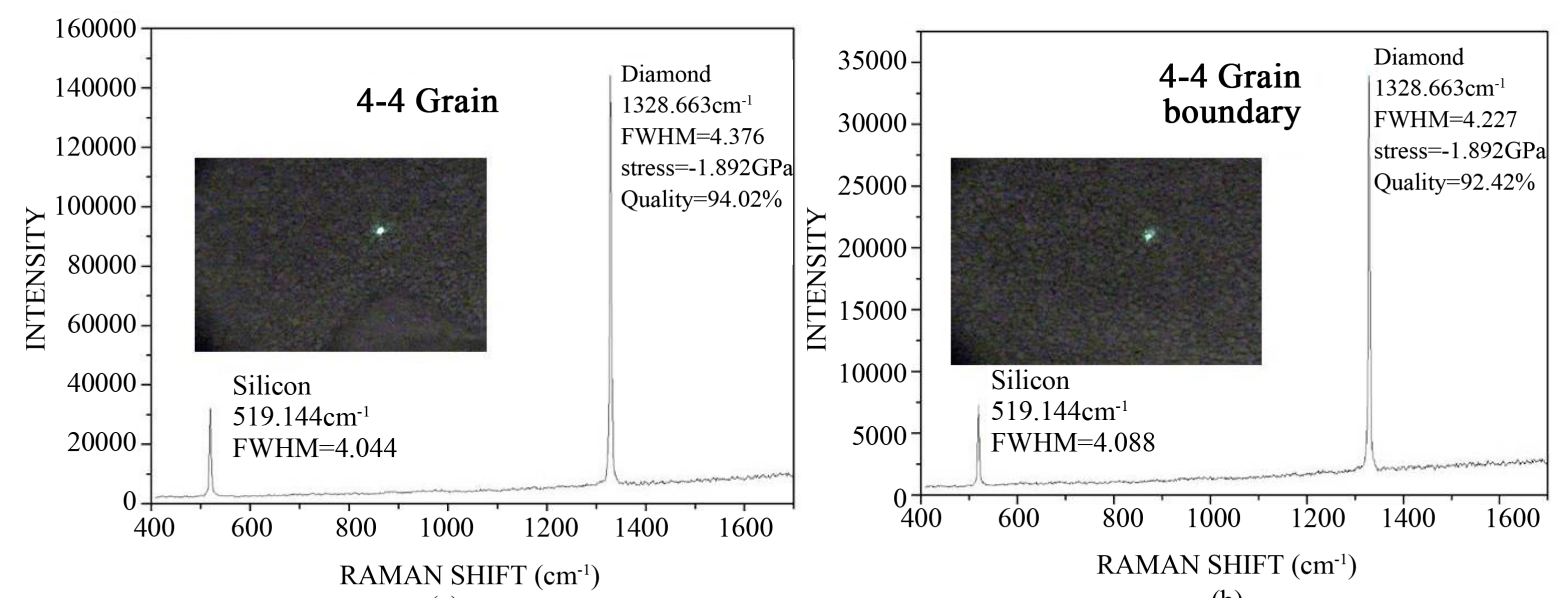

(a)

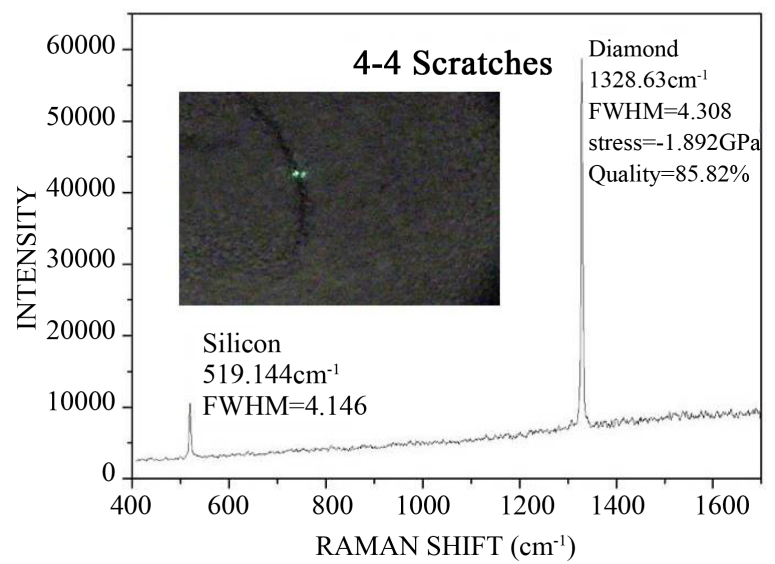

(c)

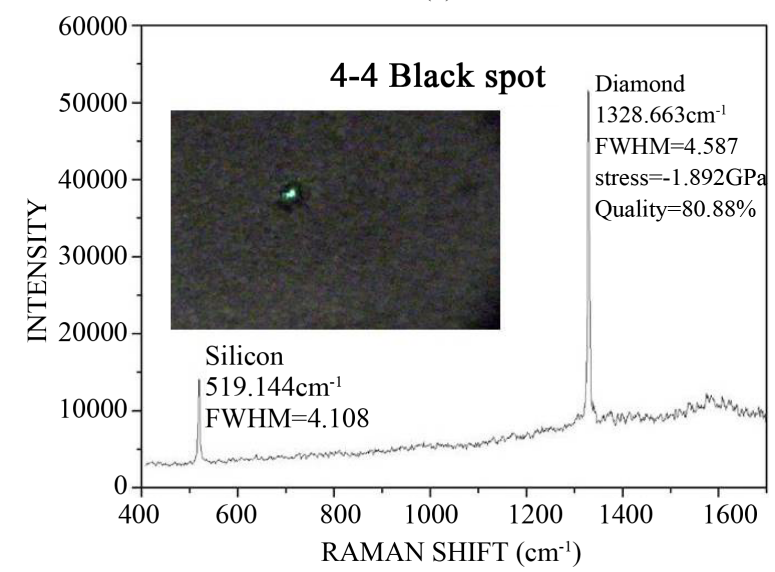

(d)

Figure 3. Raman signals of PCD coatings—from different spots on same sample. 
deteriorates from $94 \%$ to $92 \%$, as the laser point focus changes from grain to grain boundary regions, as expected. Grain size calculation by line intercept method revealed that the average grain size of each crystal for sample 4-4 is $1.21 \mu \mathrm{m}$. The size of the laser spot is $5 \mu \mathrm{m}$, which implies that at least four or five grains will fall within the laser spot. So it is very difficult to focus the laser spot inside the grain or on its grain boundary. While focussing the Raman laser, care was taken to concentrate the laser point on bigger size grain for generating reliable result on diamond quality. Moreover when the signals are taken from scratch mark (these marks are due to the mechanical polishing of the silicon wafer) or black spot on the PCD surface, the quality further deteriorates to $85 \%$ and $80 \%$ respectively. But surprisingly FWHM and internal stress were found to be more or less equal for all the regions in Figure 3. FWHM values of about $4.5 \mathrm{~cm}^{-1}$ indicate good quality PCD crystal. The stress was tensile in nature with values about $1.9 \mathrm{GPa}$. Signals from base silicon substrate were always present, indicating thin nature of the PCD coating.

\subsection{Effect of Suspension Grit Size}

Five different diamond abrasive grits were used, starting from sub-micron 0.25 micron grits through some intermediate sizes of $6-12,10-20$ and $30-40 \mu \mathrm{m}$, and to very large $40-60 \mu \mathrm{m}$ diamond particles of as described in Table 1. Effect of grit size on NNP grown PCD grain size, its quality and stress values are discussed below.

\subsubsection{PCD Grain Size}

Average PCD grains are found to be more than $2 \mu \mathrm{m}$ size, irrespective of grit sizes used (Table 2). It is observed that as we start decreasing the suspension grit size, the average PCD grain sizes diminishes but does not alter very much $(2.26-2.84 \mu \mathrm{m})$. Sub-micron grit size even after $3^{\text {rd }}$ cycle of seeding (1-3), produces big enough diamond grains. For the sake of comparison between different grit sizes only, samples which were seeded at the beginning of the seeding cycles are shown in Table 2 . For grit sizes of 5, 4 and 3 - samples prepared with $1^{\text {st }}$ seeding cycle were chosen and found to show definitive trend, whereas, for grit sizes, 2 and $1-2^{\text {nd }}, 3^{\text {rd }}$ and $5^{\text {th }}$ seeding cycles were chosen to show that lower grit sizes, even after successive uses, show better or similar results, than found for bigger grit size suspensions. It is to be noted that when the sub-micron grit size (1) is reused for the $5^{\text {th }}$ consecutive time, it gives finer diamond grains of $1.21 \mu \mathrm{m}$. The electron microscopy images of the Table 2 samples are shown in Figure 4. They show complete coverage of the silicon substrate, as all of them were seeded with relatively fresher stock of suspensions. It is to be noted that none of the Figure 4 represents sample with pre-treatment (to avoid its influence). Figure 4 compares the CVD grown PCD microstructures (10 $\mathrm{K}$ or $20 \mathrm{~K}$ magnifications) based solely on the use of different grit sizes. Even the effect of successive seeding cycle is not taken into account by comparing samples seeded within first few USP cycles. So, the lower value $1.21 \mu \mathrm{m}$ grain size of 1-5 sample compared to $2.26 \mu \mathrm{m}$ of $1-3$, even after using the same grit size, may be because of successive usage of the same diamond suspension. Figure 4(c) (sample 3-1) and Figure 4(b) (sample 4-1) show diamond octahedrals with growth steps, whereas, the other micrographs (Figure 4(e) for sample 1-3, Figure 4(d) for sample 2-2 and Figure 4(a) for sample 5-1) show crystals with signs of secondary nucleation on their surfaces. Figure 2(a), Figure 2(c) and Figure 2(d) are the optical micrographs of the electron microscopy images Figure 4(c), Figure 4(d) and Figure 4(e). It was discussed earlier that as we increase the grit size from $0.25 \mu \mathrm{m}$ (1) to 6 - $12 \mu \mathrm{m}$ (2) and then to $10-20 \mu \mathrm{m}$ (3) for the USP, the resulting PCD grain size appear to

Table 2. Effect of suspension grit size on Raman peak FWHM, PCD quality, internal stress, grain size.

\begin{tabular}{|c|c|c|c|c|c|c|c|}
\hline $\begin{array}{l}\text { Laser spot } \\
\text { position }\end{array}$ & Sample name & $\begin{array}{l}\text { Diamond peak } \\
\text { position }\left(\mathrm{cm}^{-1}\right)\end{array}$ & $\begin{array}{c}\text { Silicon peak } \\
\text { position }\left(\mathrm{cm}^{-1}\right)\end{array}$ & $\begin{array}{c}\text { FWHM of } \\
\text { diamond peak }\end{array}$ & $\begin{array}{l}\text { Stress } \\
(\mathrm{GPa})\end{array}$ & Quality (\%) & $\begin{array}{l}\text { Grain size } \\
\quad(\mu \mathrm{m})\end{array}$ \\
\hline Grain & $5-1$ & 1327.70 & 521.28 & 12.50 & 2.44 & 76.98 & 2.84 \\
\hline Grain & $4-1$ & 1330.58 & 520.21 & 3.40 & 0.80 & 94.93 & 2.64 \\
\hline Grain & $3-1$ & 1329.62 & NOT FOUND & 3.52 & 1.35 & 94.15 & 2.60 \\
\hline Grain & $2-2$ & 1329.62 & 521.28 & 5.90 & 1.35 & 94.73 & 2.40 \\
\hline Grain & $1-3$ & 1331.54 & 520.21 & 3.88 & 0.26 & 93.96 & 2.26 \\
\hline Grain & $1-5$ & 1328.66 & 519.14 & 7.40 & 1.90 & 89.65 & 1.21 \\
\hline
\end{tabular}



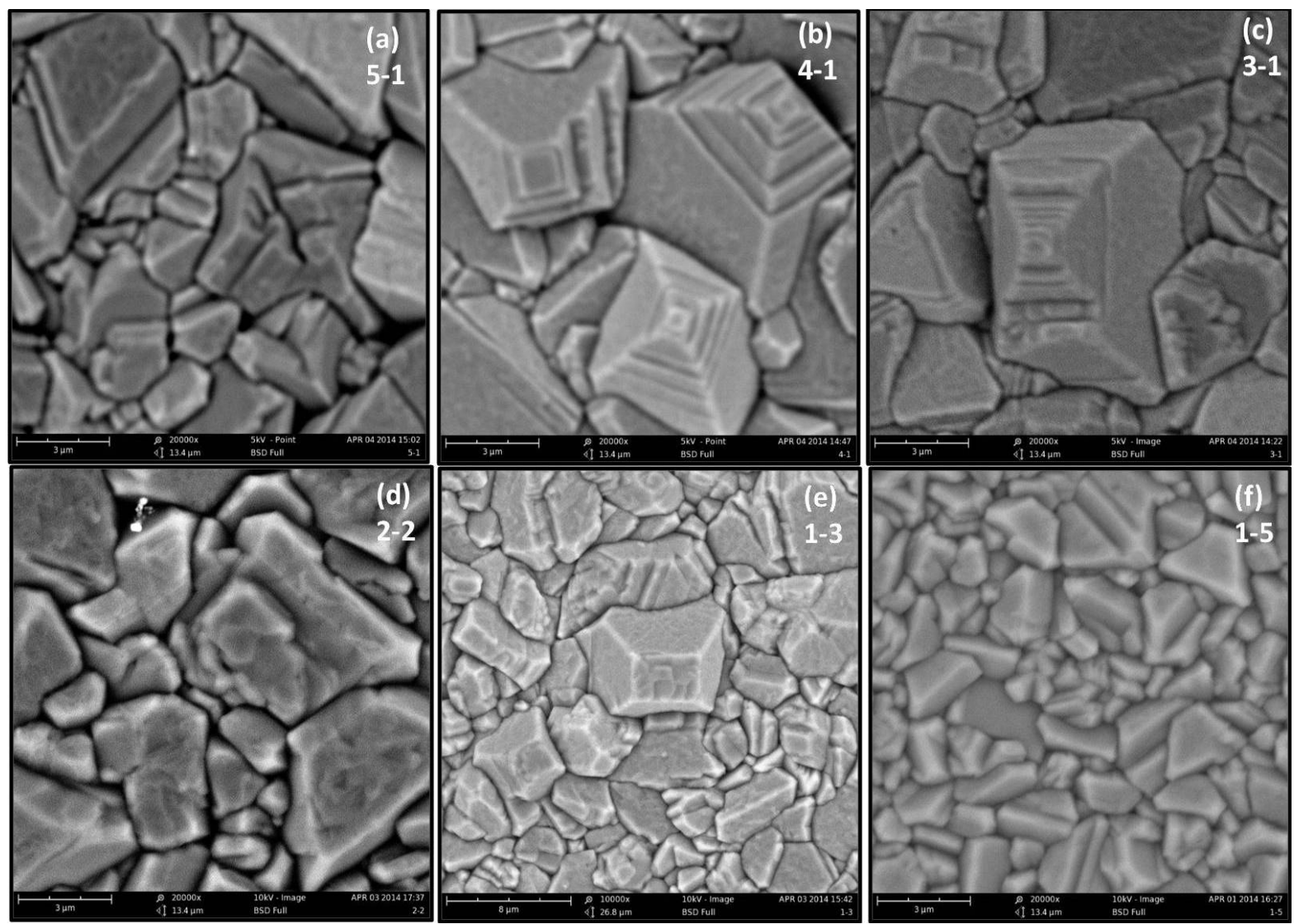

Figure 4. SEM images of fully covered PCD coatings without substrate pre-treatment.

increase gradually. Grain size calculations from SEM pictures by line intercept method show that, indeed the PCD crystal size increase with increase in grit size, although marginally (Table 2).

\subsubsection{Quality \& Stress}

Detailed analysis of the Raman signals from inside of the PCD grains (for the samples shown in Figure 2 and Figure 4) are shown in Table 2. It is found that use of very large size diamond grit may degrade ( 76\%) the deposited PCD quality with very high amount of tensile stress (sample 5-1). It will also decrease the crystallinity of the PCD grain with very high FWHM $\left(12.5 \mathrm{~cm}^{-1}\right)$. As we reduce the grit size successively from 30-40 $\mu \mathrm{m}$ down to $0.25 \mu \mathrm{m}$ submicron particle suspension, the CVD grown PCD quality does not change very much (around 94\%). The diamond peak positions are also found to be in and around $1330 \mathrm{~cm}^{-1}$, i.e. keeping the internal stress within 0 - 2 GPa. The least amount of stress is found in sample 1-3, whereas, the highest stress is found in sample 5-1. Although there is no definitive correlation between the coating material internal stress and the seed particle size, it appears that using very large diamond grit of $40-60 \mu \mathrm{m}$ deteriorates the properties of CVD grown PCD in terms of internal stress, quality and crystallinity. Sample 1-5 was prepared by seeding the silicon substrate with 5 time's reused sub-micron diamond suspension 1, which produces very fine grain (1.21 $\mu \mathrm{m})$ microstructure (Figure 4(f)). Fine grains are responsible for the loss of crystallinity as well, as Table 2 shows quite high $7.40 \mathrm{~cm}^{-1}$ FWHM for 1-5 sample.

\subsection{Effect of Successive Seeding}

Now after seeing the effect of suspension grit size on CVD growth of PCD, it is necessary to investigate the effect of successive seeding of the same grit size suspension on the features of PCD coatings. Earlier, samples with initial seeding cycles were only discussed. Now samples which were seeded later on with the reuse of the same diamond grit suspension will be discussed. 


\subsubsection{Grain Size}

10 - $20 \mu \mathrm{m}$ grit size seeding suspension (Table 1, suspension 3) was reused ten times, just like for other seeding suspensions. When the grain sizes of the resultant PCD material are compared, it is observed that there is a gradual decrease of average PCD grain size with successive seeding with the same solution. At the $1^{\text {st }}$ cycle, the sample 3-1 was producing considerable big grains of 2.4 , but with the $3^{\text {rd }}, 4^{\text {th }}$ and $6^{\text {th }}$ successive cycles, grain size gradually reduces to $2.12 \mu \mathrm{m}$ (3-3), $1.54 \mu \mathrm{m}$ (3-4) and $1.18 \mu \mathrm{m}$ (3-6) respectively (Table 3). It may be thought that with repetitive ultra-sonication of the same suspension, the size of the diamond particles decreases with disintegration of their agglomeration etc. So as the number of seeding cycles is increased the particle size of individual seeds decreases, giving rise to finer PCD microstructures (as discussed in sub-section 3.1.1). But with an exception for 3-9, as the $10-20 \mu \mathrm{m}$ grit size particle suspension on use for the $9^{\text {th }}$ successive time, produces $1.5 \mu \mathrm{m}$ size PCD grains, somewhat similar to sample 3-4. This may be because as we successively use the same suspension the seeding efficiency decreases, (with depletion of seed particles present in suspension) with discontinuous PCD coverage on the silicon substrates. So the individual crystal size may become bigger under CVD growth condition with improper coalescence, which is further discussed in the next sub-section 3.2.2.

\subsubsection{Microstructure: Full or Discontinuous Substrate Coverage}

EDAX elemental analysis was done on the NNP grown PCD coatings in order to know the chemical nature of the films. It is seen that 3-5 sample ( $5^{\text {th }}$ seeding cycle) shows almost full coverage (pockets of the base substrate are also visible, as circled in the Figure $5(\mathrm{a})$ ) of the silicon substrate, whereas at the $9^{\text {th }}$ seeding cycle, even for

Table 3. Effect of successive use of diamond seeding suspension on CVD grown PCD grain sizes.

\begin{tabular}{ccc}
\hline Sample & Grain Size \\
\hline $3-1$ & 2.40 \\
$3-3$ & 2.12 \\
$3-4$ & 1.54 \\
$3-6$ & 1.18 \\
$3-9$ & 1.50 \\
\hline
\end{tabular}

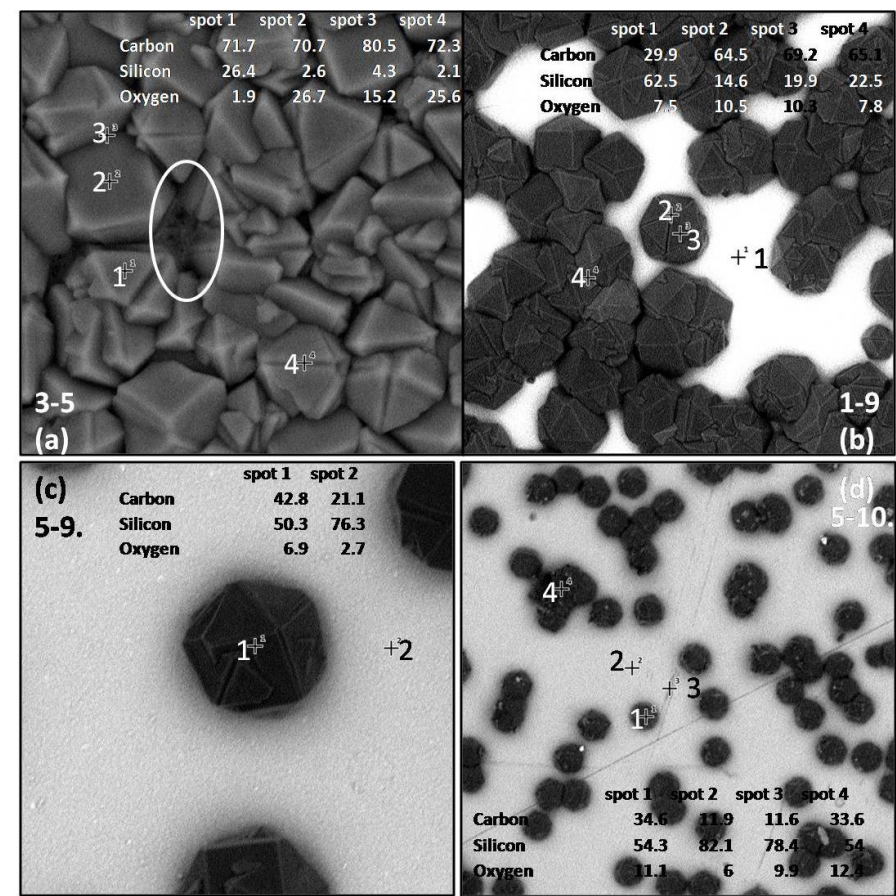

Figure 5. EDAX spot analysis images of PCD coatings, showing discontinuous growth $5^{\text {th }}$ seeding cycle onwards. 
the sample seeded with submicron grit size (1 is known for high seeding efficiency), there is discontinuous growth of PCD (Figure 5(b)). When the biggest diamond grit size (not known for efficient seeding) of 40 - 60 $\mu \mathrm{m}$ was used in successive seeding for the $9^{\text {th }}$ and $10^{\text {th }}$ consecutive times, even substrate pre-treatment (known for enhancing nucleation density) could not induce full substrate coverage on NNP growth of PCD coatings (Figure 5(c) and Figure 5(d)). EDAX spot analysis was done for grain, grain boundary, isolated grains, bare silicon substrate regions. EDAX signals from grain and grain boundary regions (1, 2, 3 \& 4 spots in Figure 5(a), 2, 3, 4 spots in Figure 5(b)) give predominant presence of carbon, whereas, the EDAX peaks from whitish uncovered base region (spot 1 in Figure 5(b); spot 2 in Figure 5(c); spots 2 \& 3 in Figure 5(d)) show more percentages of silicon. The areas where no diamond grains are visible may be covered with amorphous carbon. Moreover, since the percentage concentration of silicon is higher, it may be inferred that there are phases like silicon carbide. It is interesting to note that some of the isolated PCD grains are producing almost $50 \%$ concentration silicon peaks (spot 1 in Figure 5(c) and spots $1 \& 4$ in Figure 5(d)). They may reveal the presence of silicon carbide phases.

\subsubsection{Quality \& Stress}

Sub-micron grit suspensions are known as efficient seeding material. Earlier result indicates that sample seeded with $0.25 \mu \mathrm{m}$ diamond grit produces good quality PCD (Table 2, last two rows describing samples 1-3 and 1-5). In order to show the effect of seeding cycle efficiency on PCD quality, internal stress and the Raman peak width at half maxima using suspension 1 , few more examples in this set of samples (1-4, 1-8, 1-9 \& 1-10) are described in Table 4 . It is found that with successive reuse of the same slurry 1 , after $3^{\text {rd }}, 4^{\text {th }}, 5^{\text {th }}, 6^{\text {th }}, 9^{\text {th }}$ and $10^{\text {th }}$ times, the PCD quality gradually deteriorates from $93 \%$ to $91 \%$, $89 \%, 87 \%, 69 \%$ and $60 \%$ respectively. Internal stress also successively increases from $0.26 \mathrm{GPa}$ (sample 1-3) to $2.44 \mathrm{GPa}$ (sample 1-9), within the resultant PCD films, exception being the 1-10 sample which has 0.8 GPa stress similar to sample 1-4. Later in the sub-section 3.3.1, it will be further discussed that 1-10 also has deviated grain size value, mainly because of successive seeding.

The Raman signals were taken from within the grain and in case of discontinuous growth (incomplete substrate coverage), grains lying inside the covered region were studied. The crystallinity (FWHM) of the PCD grains also fall with the use of successive seeding, from $3.88 \mathrm{~cm}^{-1}$ (sample 1-3) down to $11.36 \mathrm{~cm}^{-1}$ (sample 1-9), again with a slight trend reversal for sample $1-10$. Silicon peak at $520.5 \mathrm{~cm}^{-1}$ is noticed always, as the PCD coatings were thin enough to get Raman signal from the base Si substrate. The general trend is that with successive use of same seeding slurry, resulting PCD becomes poorer.

\subsection{Effect of PT}

So far the effect of abrasive grit size and the use of successive seeding cycles on the CVD growth of polycrystalline diamond films have been discussed. But the most significant parameter is the substrate surface pre-treatment (PT) on the nucleation enhancement, which makes the process termed as "NNP". Samples marked with (.) were pre-treated inside hot filament CVD chamber for a brief period of time. PT facilitates diamond nucleation during CVD growth (GC). Pre-treatment of bare silicon substrate under diamond growth conditions leaves a carbon film on the surface which supplies carbon material during initial nucleation and growth process of the diamond CVD (GC). PT was done under GC which means that the carbon film that formed under conditions didn't leave any sp2 bonded carbon on the growing surface, as the hydrogen would have etched them away. Initial 10 - $15 \mathrm{~nm}$ of carbon film formed during PT was almost 100\% sp3 bonded carbon in an amorphous form

Table 4. Effect of successive use of diamond seeding suspension on CVD grown PCD peak width, stress and quality.

\begin{tabular}{cccccccc}
\hline $\begin{array}{c}\text { Laser spot } \\
\text { position }\end{array}$ & $\begin{array}{c}\text { Sample } \\
\text { name }\end{array}$ & $\begin{array}{c}\text { Diamond peak } \\
\text { position }\left(\mathrm{cm}^{-1}\right)\end{array}$ & $\begin{array}{c}\text { Silicon peak } \\
\text { position }\left(\mathrm{cm}^{-1}\right)\end{array}$ & $\begin{array}{c}\text { FWHM of } \\
\text { diamond peak }\end{array}$ & $\begin{array}{c}\text { Stress } \\
(\mathrm{GPa})\end{array}$ & $\begin{array}{c}\text { Quality } \\
(\%)\end{array}$ & Grain size $(\mu \mathrm{m})$ \\
\hline Grain & $1-4$ & 1330.58 & 520.21 & 4.72 & 0.80 & 91.56 & 1.28 \\
Grain & $1-8$ & 1328.66 & 520.21 & 8.03 & 1.90 & 87.00 & $\begin{array}{c}\text { Discontinuous } \\
\text { Discontinuous } \\
\text { Figure 6(k) }\end{array}$ \\
Grain & $1-9$ & 1327.70 & 519.14 & 11.36 & 2.44 & 69.94 & 1.43 \\
\hline
\end{tabular}


[49]. Afterwards, seeding with pure diamond grit was done, avoiding any use of the detonation nanodiamond and by the ultrasonic action the grit left behind small diamond particles, much smaller than the grit size, that were partly embedded inside the sea of the sp3 carbon. The diamond particles under ultrasonic agitation, would interact with the carbon film on silicon substrate, creating activated surface sites (pits, channels, edges, corners etc.) for nucleation. It may be termed as the nucleation film. Then when the GC started, these seeds commenced growing using the PT carbon film in a way transforming it into the crystalline form, in what can be like a re-crystallization action. This is the reason that the incubation time is very short and the growth is done laterally as the seeds grow sidewise until they touch each other. This is also the reason that the interface is very smooth with very little crevices for NNP grown films [55]. Following sub-sections discuss the effect of PT on NNP grown PCD grain size, quality, crystallinity and internal stress.

\subsubsection{Grain Size}

Submicron seed particles are known for enhancing the nucleation and growth of PCD better than micron size grits. So from the seeding efficiency point of view, the discussion is limited to suspension 1 only. Other particle sizes (2, 3, 4 \& 5) are not included in Table 4 \& Table 5, in order to remove the influence of the "grit size" parameter on the result. When the $4^{\text {th }}, 5^{\text {th }}$ and $10^{\text {th }}$ seeding cycle samples, i.e. those prepared with older stock suspension of sub-micron grits, are compared between their pairs (1-4 \& 1-4. $-1.28 \mu \mathrm{m} \& 1.39 \mu \mathrm{m} ; 1$ 1-5 \& 1-5. $-1.21 \mu \mathrm{m} \& 1.60 \mu \mathrm{m} ; 1-10 \& 1-10 .-1.43 \mu \mathrm{m} \& 1.78 \mu \mathrm{m}$ respectively) as described in Table 2, Table 4 and Table 5), it is found that the samples without substrate pre-treatment produce smaller size PCD grains. Although, this trend is not shown for the sample pairs prepared with fresh stock of seeding suspension (i.e. between samples 1-3 \& 1-3. $-2.26 \mu \mathrm{m} \& 1.60 \mu \mathrm{m})$. It is observed that there is difference in grain sizes between pair of samples prepared with or without PT. Sample pairs when seeded with fresh stock of suspension ( ${ }^{\text {rd }}$ cycle) they show decrease in grain size (from 2.26 to $1.60 \mu \mathrm{m}$ ), when the sample is pre-treated (Figure 2(a) and Figure 2(b) with Table 2 \& Table 5). But the reverse is true for NNP sample seeded with older stock suspensions. So it is seen that successive use of seeding suspension influence significantly the grain sizes of the PCD samples, may be it has stronger influence than PT effect.

In the earlier sub-section 3.2.1, it was noticed that as the cycle number is increased for suspension 3, application of more ultrasonic force disintegrates the diamond seed particle in the suspension, which produces finer PCD microstructure (Table 3). Similar trend is also observed for suspension 1 (Table 2 \& Table 4). The grain sizes for sample 1-3 $(2.26 \mu \mathrm{m}), 1-4(1.28 \mu \mathrm{m})$ and 1-5 $(1.21 \mu \mathrm{m})$ gradually diminish with successive use of ultrasonic force. On the other hand just like suspension 3 , suspension 1 also has reverse trend of increased grain size (3-9 shows $1.5 \mu \mathrm{m}$ and 1-10 shows $1.43 \mu \mathrm{m}$ ) for higher seeding cycles. It seems that the recycling of the same suspension has very strong effect on the final PCD characteristics. Although some kind of correlation between successive seeding cycles and final grain size is noticed for without PT samples, but for PT samples no noticeable trend is observed with more or less similar grain sizes $(1.39 \mu \mathrm{m}-1-4 ., 1.41 \mu \mathrm{m}-1-5 ., 1.60$ $\mu \mathrm{m}-1$-3., $1.78 \mu \mathrm{m}-1-10$.). In other words, pre-treatment of substrate surface may overshadow the trends found in successive seeding.

\subsubsection{Quality \& Stress}

Table 2, Table 4 and Table 5 also show the Raman results of the PCD coating prepared with suspension 1, both with PT and without PT. It is observed that pre-treatment enhances (comparing each pair, with PT or without PT from Table 2, Table 4 and Table 5) the diamond coating quality, significant one being the samples prepared

Table 5. Raman and grain size data for pretreated (PT) PCD samples seeded.

\begin{tabular}{|c|c|c|c|c|c|c|c|}
\hline $\begin{array}{l}\text { Laser spot } \\
\text { position }\end{array}$ & $\begin{array}{l}\text { Sample } \\
\text { name }\end{array}$ & $\begin{array}{l}\text { Diamond peak } \\
\text { position }\left(\mathrm{cm}^{-1}\right)\end{array}$ & $\begin{array}{l}\text { Silicon peak } \\
\text { position }\left(\mathrm{cm}^{-1}\right)\end{array}$ & $\begin{array}{c}\text { FWHM of } \\
\text { diamond peak }\end{array}$ & $\begin{array}{l}\text { Stress } \\
(\mathrm{GPa})\end{array}$ & Quality (\%) & $\begin{array}{c}\text { Grain size } \\
\quad(\mu \mathrm{m})\end{array}$ \\
\hline Grain & $1-3$. & 1328.66 & 520.21 & 5.46 & 1.89 & 94.52 & 1.60 \\
\hline Grain & $1-4$. & 1329.62 & 520.21 & 7.16 & 1.35 & 93.22 & 1.39 \\
\hline Grain & $1-5$. & 1329.66 & 520.21 & 4.45 & 1.35 & 90.38 & 1.41 \\
\hline Grain & $1-8$ & 1327.70 & 519.14 & 4.75 & 2.44 & 94.91 & 1.40 \\
\hline Grain & $1-10$. & 1326.74 & 519.14 & 6.19 & 2.98 & 90.31 & 1.77 \\
\hline
\end{tabular}


using 10 successive seeding where PT enhances the quality from $60 \%$ (1-10) to $90 \%$ (1-10.). More than $90 \%$ is the average quality of the PCD coating of the PT samples. But one interesting trend is that the surface pretreatment enhances the internal stress to a significant extent (exception 1-5 pair). The explanation may be that the nature of stress present is found to be tensile. Tensile stress arises due to generation of defects during growth. The defects may be points, vacancy, dislocation, grain boundary etc. It is to be understood that the pre-treated surface produces diamond films with more growth defects. PT produces soft carbon film before diamond CVD growth. This carbon film supplies carbon atoms during diamond crystal formation in the early stages of nucleation and growth. Now when a crystal is forming from an amorphous source of carbon atoms, it is already creating vacancy in the underlying carbon film, which also influences Raman signal to significant level. If we consider the effect of successive seeding on PT results, it is found that fresh stock of suspensions (1-3 \& 1-3. -3.88 $\mathrm{cm}^{-1} \& 5.46 \mathrm{~cm}^{-1} ; 1-4 \& 1-4 .-4.72 \mathrm{~cm}^{-1} \& 7.16 \mathrm{~cm}^{-1}$ ) increase the FWHM values (decrease crystallinity) for samples with PT, whereas, the older stocks of seeding suspension $\left(1-5 \& 1-5 .-7.4 \mathrm{~cm}^{-1} \& 4.45 \mathrm{~cm}^{-1} ; 1-8\right.$ \& 1-8. $-8.03 \mathrm{~cm}^{-1} \& 4.75 \mathrm{~cm}^{-1} ; 1-10 \& 1-10 .-10.84 \mathrm{~cm}^{-1} \& 6.19 \mathrm{~cm}^{-1}$ ) decrease the FWHM values (better crystals) between pair of samples with PT. General understanding is that PT enhances nucleation or helps in faster initial growth or coverage of the silicon substrate by creating a soft carbon film which supplies carbon atoms during nucleation and initial CVD growth of diamond. Sample pairs 1-5, 1-8, 1-10 seem to show expected result of improving quality and crystallinity with PT, whereas the sample pairs 1-3 and 1-4 showed the reverse trend. Here, the role of successive seeding is supplementing the influence of PT on diamond nucleation and growth.

\subsection{NNP Grown PCD Microstructure and Quality-Coalescence}

NNP grown PCD samples were seen under microscope as depicted in Figure 6. Samples are shown at the lowest possible magnifications (Figure 6(a), Figure 6(e) and Figure 6(g)) in order to understand the shape and size of the individual silicon samples. Red square on each sample denotes the area under next higher magnifications. Figure 6(b) shows magnified view of the smaller highlighted red square in Figure 6(a). Similarly Figure 6(c) and Figure 6(d) show successive higher magnifications of the sample 4-9., which was prepared following all the three NNP steps, namely PT, USP and GC respectively. The grit size used was 30 - $40 \mu \mathrm{m}$ and the seeding suspension was used successively for 9 times. Such exhausted big particle slurry is found to be ineffective in producing continuous growth over susbstrate but PT seems to have helped them in more or less complete coverage, since the sample 4-10 (for the sake of argument it is mentioned that authors found 4-9 and 4-10 samples were almost identical from coalescence perspective, but 4-10 was chosen for SEM sample preparation) prepared with same suspension but without susbstrate pretreatment is found to be completly uncovered as shown in Figure 6(e) and Figure 6(f). Comparing Figure 6(a) and Figure 6(e), it can be conclusively stated that PT helps in effective film coverage on siliocn substrates. Similar to 4-9., sample 5-9., which was prepepared with larger grit size of 40 $60 \mu \mathrm{m}$ in $9^{\text {th }}$ successive seeding cycle and with PT, is found to be discontinuous. The degree of discontinuity (compare Figure 6(a) and Figure 6(g)) is more for 5-9. than 4-9., may be because of the inefficiency of seeding by bigger grit sizes. Some circular patch marks are seen for the samples 4-10 and 5-9. in Figure 6(e) and Figure 6(g). The sizes of the patch marks are bigger and more covered, in Figure 6(g) and Figure 6(h) than Figure 6(e), may be because of the combination of both the effects, bigger grit size and PT. So, PT seems to facilitate substrate coverage and helps to overcome the negative effect of using bigger seed particles.

If the samples prepared with comparatively less exhausted seeding suspensions are compared, it is seen that sample seeded with smaller grit size (sample 3-6 in Figure 6(i)), even without preptreatment, gives more susbtrate covereage than Figure 6(a)-(h). Figure 6(i) shows distinct linear seeding patterns which had been imprinted on the substrate during the mechanical polishing of the silicon substrate and was followed on during CVD growth (GC) of diamond. The size of the isolated PCD crystal is found to be around $7 \mu \mathrm{m}$ (Figure 6(j)). It may be somewhat larger considering the fact that the individual nucleation site grows on its own without competition from the neighbouring crystallites. Use of smaller seed particles help in getting faster substrate coverage. Successive seeding may be the most detrimental factor in effective diamond seeding for NNP nucleation and growth. From $5^{\text {th }}$ seeding cycle (Figure 5(a)) onwards the seeding solution appears to become ineffective (may be termed as old solution) in prodcuing PCD with complete substrate coverage. But usage of sub-micron grit size may significantly overcome the drawback of successive seeding as shown in Figure 6(k) and Figure 6(l), where even after 9 times use of the same slurry, NNP without PT produces almost complete coverage. It was just a matter of time had the susbstrate been given sufficient deposition period, it would have been completely covered. 

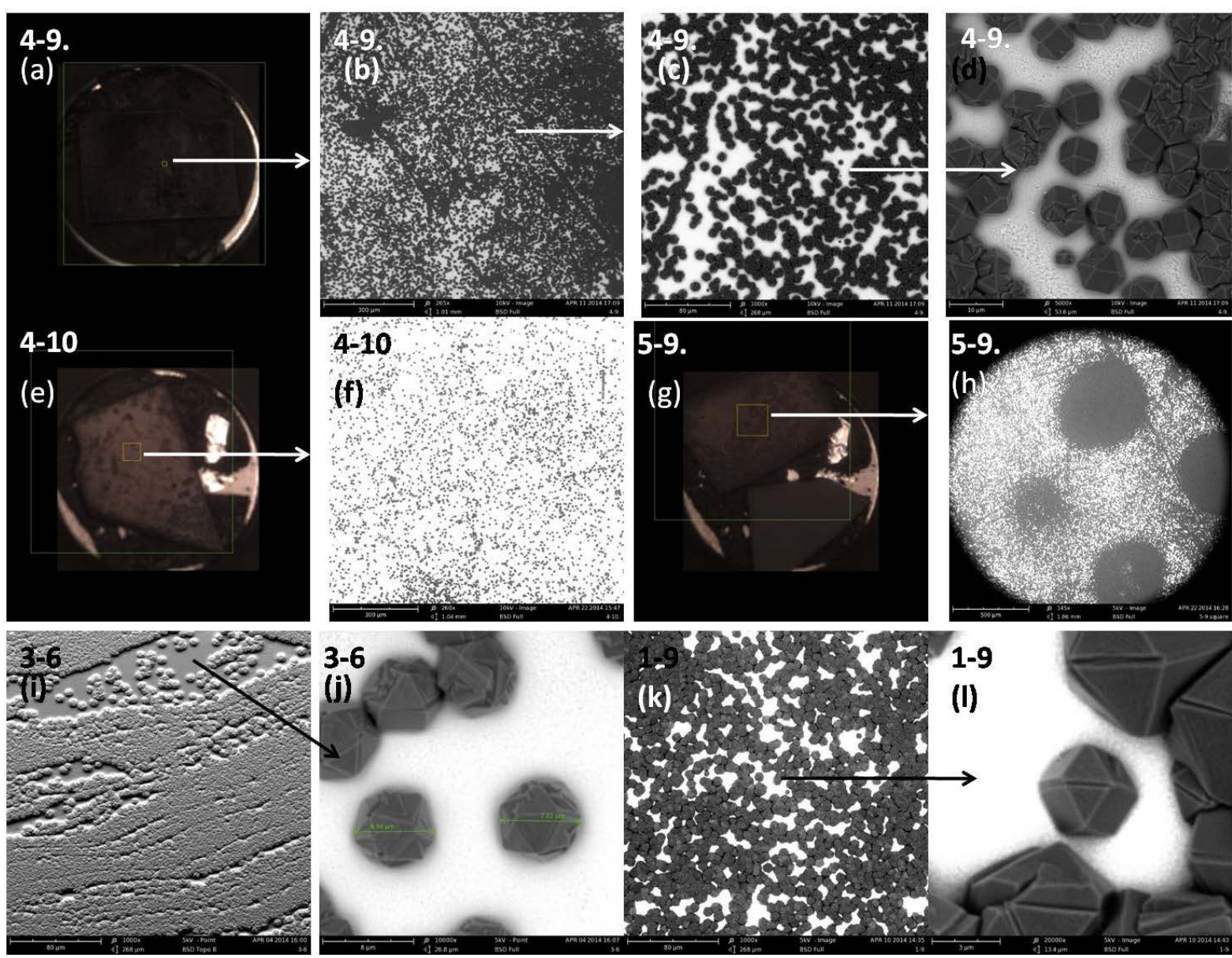

Figure 6. SEM images of PCD coatings showing discontinuous growth with older $\left(>5^{\text {th }}\right.$ cycles) suspension stocks.

\section{Conclusions}

A large batch of samples were systematically prepared to study the effect of substrate surface pretreatment (PT), reuse of seeding suspension (USP cycles) and suspension grit size on the nucleation and growth behavior of polycrystalline diamond coatings on siliocn substrate. Novel nucleation process (NNP) was compared with normal ultrasonication seeding procedure by diamond grit suspensions and followings are the experimental outcomes:

1) Decreasing the seeding suspension grit size (from 40 - $60 \mu \mathrm{m}$ to $0.25 \mu \mathrm{m}$ ) diminishes the average PCD grain sizes $(2.84 \mu \mathrm{m}-2.26 \mu \mathrm{m})$ marginally.

2) Quality and crystallinity of PCD coatings are satisfactorily high ( 94\%) with usage of different grit sizes, but usage of the biggest seed particle size considerably degrades the quality (76\%) and its crystallinity (FWHM $12.5 \mathrm{~cm}^{-1}$ ) with introduction of large internal stress (2.44 GPa).

3) Successive reuse of the same diamond suspension $\left(1^{\text {st }}, 2^{\text {nd }}, 3^{\text {rd }}\right.$ and so on) for seeding silicon substrates, progressively decreases the resulting PCD grain sizes, may be because, successive use of the ultrasonic force disintegrates the large diameter grits into smaller ones.

4) Quality of the resulting PCD coatings suffers very much (1-10 shows 60\%) with the reuse of same diamond suspensions for seeding.

5) $6^{\text {th }}$ seeding cycle onwards, discontinuous growth (1-8 \& 1-9) of PCD occurs, which can be improved with PT of substrate (1-8. \& 1-9.).

6) $\mathrm{PT}$ of the silicon substrate before USP, appears to help in improving diamond film quality from $60 \%$ to $90 \%$ (1-10 \& 1-10.).

7) Successive use of the same diamond suspension is found to be very much detrimental in terms of continuous growth of PCD over the silicon substrates. PT can somewhat overshadow that effect but not to a great extent. 
8) Since the diamond seeding suspensions are not in nanometer dimension (no detonation nano diamond slurry was used), NNP is observed to be very sensitive to recycling of the same suspension for successive seeding.

9) However, reducing seed particle size helps in grain coalescence wherein sub-micron grit size is found to be the most efficient seeding material.

This work is different from earlier findings [55] which were for growing UNCD film with argon rich plasma chemistry. Here we report the effectiveness of HFCVD pre-treatment [49] with diamond abrasive seeding procedure for growing polycrystalline diamond coatings using $915 \mathrm{MHz}$ CVD reactor. It is found that the NNP process of combining PT with sub-micron diamond particle seeding by ultrasonication is very effective in enhancing CVD nucleation and growth of PCD coatings.

\section{Acknowledgements}

The financial support was from the Council of Scientific and Industrial Research (CSIR) network project MTDDC, PSC0101 and Department of Science and Technology (DST) sponsored international Indo-Russian S\&T program GAP0246. This work was also funded by FCT/MEC through Portuguese funds and when applicable co-funded by FEDER-PT2020 partnership agreement under the project UID/EEA/50008/2013. J. C. Mendes also acknowledges the FCT for the grant BPD/90306/2012. Authors acknowledge the technical assistance of Mr. Nandadulal Dandapat and Ms Anuradha Jana. Prof. Arun Kumar Pal guided us in understanding many research concepts. Dean, Faculty of Science, Jadavpur University and Director, CSIR-CGCRI are also acknowledged for their permissions.

\section{References}

[1] Angus, J.C. (2014) Diamond Synthesis by Chemical Vapor Deposition: The Early Years. Diamond \& Related Materials, 49, 77-86. http://dx.doi.org/10.1016/j.diamond.2014.08.004

[2] Bundy, F.P., Hall, H.T., Strong, H.M. and Wentorf Jr., R.J. (1955) Manmade Diamond. Nature, 176, 51-54. http://dx.doi.org/10.1038/176051a0

[3] Eversole, W. (1962) Synthesis of Diamond. US Patent 3,030,188.

[4] Derjaguin, B.V., Fedoseev, D.V., Lukyanovich, V.M., Spitzin, B.V. and Lavrentyev, A.V. (1968) Filamentary Diamond Crystals. Journal of Crystal Growth, 2, 380-384. http://dx.doi.org/10.1016/0022-0248(68)90033-X

[5] Spitsyn, B.V., Bouilov, L.L. and Derjaguin, B.V. (1981) Vapor Growth of Diamond on Diamond and Other Surfaces. Journal of Crystal Growth, 52, 219-226. http://dx.doi.org/10.1016/0022-0248(81)90197-4

[6] Deryagin, B.V., Dzevitsky, B.E., Kochkin, D.A. and Spitsyn, B.V. (1972) Producing Diamonds Synthetically. US Patent 3705937 A.

[7] Angus, J.C., Will, H.A. and Stanko, W.S. (1968) Growth of Diamond Seed Crystals by Vapor Deposition. Journal of Applied Physics, 39, 2915. http://dx.doi.org/10.1063/1.1656693

[8] Angus, J.C. (2002) Diamond Films Handbook. Meckel Dekker Inc., New York, 17-26.

[9] Matsumoto, S., Sato, Y., Tsutsumi, M. and Setaka, N. (1982) Growth of Diamond Particles from Methane-Hydrogen Gas. Journal of Materials Science, 17, 3106-3112. http://dx.doi.org/10.1007/BF01203472

[10] Kamo, M., Sato, Y., Matsumoto, S. and Setaka, N. (1983) Diamond Synthesis from Gas Phase in Microwave Plasma. Journal of Crystal Growth, 62, 642-644. http://dx.doi.org/10.1016/0022-0248(83)90411-6

[11] De Vries, R.C. (1987) Synthesis of Diamond under Metastable Conditions. Annual Review of Materials Science, 17, 161-187. http://dx.doi.org/10.1146/annurev.ms.17.080187.001113

[12] Wang, C.X. and Yang, G.W. (2005) Thermodynamics of Metastable Phase Nucleation at the Nanoscale. Materials Science and Engineering R, 49, 157-202. http://dx.doi.org/10.1016/j.mser.2005.06.002

[13] Zhang, C.Y., Wang, C.X., Yang, Y.H. and Yang, G.W. (2004) A Nanoscaled Thermodynamic Approach in Nucleation of CVD Diamond on Nondiamond Surfaces. Journal of Physical Chemistry B, 108, 2589-2593. http://dx.doi.org/10.1021/jp036887d

[14] Nemanich, R.J., Carlisle, J.A., Hirata, A. and Haenen, K. (2014) CVD Diamond—Research, Applications, and Challenges. MRS Bulletin, 39, 490-494. http://dx.doi.org/10.1557/mrs.2014.97

[15] Schwander, M. and Partes, K. (2011) A Review of Diamond Synthesis by CVD Processes. Diamond \& Related Materials, 20, 1287-1301. http://dx.doi.org/10.1016/j.diamond.2011.08.005

[16] Mallik, A.K., Mendes, J.C., Rotter, S.Z. and Bysakh, S. (2014) Detonation Nanodiamond Seeding Technique for Nucleation Enhancement of CVD Diamond-Some Experimental Insights. Advances in Ceramic Science and Engineer- 
ing, 3, 36-45. http://dx.doi.org/10.14355/acse.2014.03.005

[17] Lee, S.T., Lin, Z. and Jiang, X. (1999) CVD Diamond Films: Nucleation and Growth. Materials Science and Engineering R, 25, 123-154. http://dx.doi.org/10.1016/S0927-796X(99)00003-0

[18] Smolin, A.A., Ralchenko, V.G., Pimenov, S.M., Kononenko, T.V. and Loubnin, E.N. (1993) Optical Monitoring of Nucleation and Growth of Diamond Films. Applied Physics Letters, 62, 3449-3451. http://dx.doi.org/10.1063/1.109045

[19] Liu, H. and Dandy, D.S. (1995) Studies on Nucleation Process in Diamond CVD: An Overview of Recent Development. Diamond and Related Materials, 4, 1173-1188. http://dx.doi.org/10.1016/0925-9635(96)00297-2

[20] Popovici, G. and Prelas, M.A. (1992) Nucleation and Selective Deposition of Diamond Thin Films. Physica Status Solidi, 132, 233-252. http://dx.doi.org/10.1002/pssa.2211320202

[21] Kromka, A., Potocký, S., Čermák, J., Rezek, B., Potměšil, J., Zemek, J. and Vaněček, M. (2008) Early Stage of Diamond Growth at Low Temperature. Diamond \& Related Materials, 17, 1252-1255. http://dx.doi.org/10.1016/j.diamond.2008.03.035

[22] Chavanne, A., Barjon, J., Vilquin, B., Arabski, J. and Arnault, J.C. (2012) Surface Investigations on Different Nucleation Pathways for Diamond Heteroepitaxial Growth on Iridium. Diamond \& Related Materials, 22, 52-58. http://dx.doi.org/10.1016/j.diamond.2011.12.005

[23] Naguib, N.N., Elam, J.W., Birrell, J., Wang, J., Grierson, D.S., Kabius, B., Hiller, J.M., Sumant, A.V., Carpick, R.W., Auciello, O. and Carlisle, J.A. (2006) Enhanced Nucleation, Smoothness and Conformality of Ultrananocrystalline Diamond (UNCD) Ultrathin Films via Tungsten Interlayers. Chemical Physics Letters, 430, 345-350. http://dx.doi.org/10.1016/j.cplett.2006.08.137

[24] Mallik, A.K., Binu, S.R., Satapathy, L.N., Narayana, C., Seikh, M.M., Shivashankar, S.A. and Biswas, S.K. (2010) Effect of Substrate Roughness on Growth of Diamond by Hot Filament CVD. Bulletin of Materials Science, 33, 251-255. http://dx.doi.org/10.1007/s12034-010-0039-3

[25] Lin, S.J., Lee, S.L., Hwang, J., Chang, C.S. and Wen, H.Y. (1992) Effects of Local Facet and Lattice Damage on Nucleation of Diamond Grown by Microwave Plasma Chemical Vapor Deposition. Applied Physics Letters, 60, 15591561. http://dx.doi.org/10.1063/1.107250

[26] Das, D. and Singh, R.N. (2007) A Review of Nucleation, Growth and Low Temperature Synthesis of Diamond Thin Film. International Materials Reviews, 52, 29-64. http://dx.doi.org/10.1179/174328007X160245

[27] Bogdanowicz, R., Śmietana, M., Gnyba, M., Gołunski, L., Ryl, J. and Gardas, M. (2014) Optical and Structural Properties of Polycrystalline CVD Diamond Films Grown on Fused Silica Optical Fibres Pre-Treated by High-Power Sonication Seeding. Applied Physics A, 116, 1927-1937. http://dx.doi.org/10.1007/s00339-014-8355-x

[28] Pobedinskas, P., Janssens, S.D., Hernando, J., Wagnera, P., Nesládek, M. and Haenen, K. (2011) Selective Seeding and Growth of Nanocrystalline CVD Diamond on Non-Diamond Substrates. MRS Proceedings, 1339, 04-02. http://dx.doi.org/10.1557/opl.2011.992

[29] Fox, O.J.L., Holloway, J.O.P., Fuge, G.M., May, P.W. and Ashfold, M.N.R. (2009) Electrospray Deposition of Diamond Nanoparticle Nucleation Layers for Subsequent CVD Diamond Growth. MRS Proceedings, 1203, J17-J27.

[30] Iijima, S., Aikawa, Y. and Baba, K. (1990) Early Formation of Chemical Vapor Deposition Diamond Films. Applied Physics Letters, 57, 2646-2648. http://dx.doi.org/10.1063/1.103812

[31] Liu, X., Yu, T., Wei, Q., Yu, Z. and Xu, X. (2012) Enhanced Diamond Nucleation on Copper Substrates by Employing an Electrostatic Self-Assembly Seeding Process with Modified Nanodiamond Particles. Colloids and Surfaces A: Physicochemical and Engineering Aspects, 412, 82-89. http://dx.doi.org/10.1016/j.colsurfa.2012.07.020

[32] Arnault, J.C., Demuynck, L., Speisser, C. and Normand, F.L. (1999) Mechanisms of CVD Diamond Nucleation and Growth on Mechanically Scratched Si(100) Surfaces. The European Physical Journal B-Condensed Matter and Complex Systems, 11, 327-343. http://dx.doi.org/10.1007/s100510050943

[33] Podesta, A., Salerno, M., Ralchenko, V., Bruzzi, M., Sciortino, S., Khmelnitskii, R. and Milani, P. (2006) An Atomic Force Microscopy Study of the Effects of Surface Treatments of Diamond Films Produced by Chemical Vapor Deposition. Diamond \& Related Materials, 15, 1292-1299. http://dx.doi.org/10.1016/j.diamond.2005.10.005

[34] Anger, E., Gicquel, A., Wang, Z.Z. and Ravet, M.F. (1995) Chemical and Morphological Modifications of Silicon Wafers Treated by Ultrasonic Impacts of Powders: Consequences on Diamond Nucleation. Diamond \& Related Materials, 4, 759-764. http://dx.doi.org/10.1016/0925-9635(94)05301-4

[35] Shenderova, O., Hens, S. and McGuire, G. (2010) Seeding Slurries Based on Detonation Nanodiamond in DMSO. Diamond \& Related Materials, 19, 260-267. http://dx.doi.org/10.1016/j.diamond.2009.10.008

[36] Williams, O.A., Douheret, O., Daenen, M., Haenen, K., Osawa, E. and Takahashi, M. (2007) Enhanced Diamond Nucleation on Monodispersed Nanocrystalline Diamond. Chemical Physics Letters, 445, 255-258. http://dx.doi.org/10.1016/j.cplett.2007.07.091 
[37] Ralchenko, V., Saveliev, A., Voronina, S., Dementjev, A., Maslakov, K., Salerno, M., Podesta, A. and Milani, P. (2005) Nanodiamond Seeding for Nucleation and Growth of CVD Diamond Films; Synthesis, Properties and Applications of Ultrananocrystalline Diamond. NATO Science Series, 192, 109-124. http://dx.doi.org/10.1007/1-4020-3322-2_9

[38] Chen, Y.C., Zhong, X.Y., Konicek, A.R. and Grierson, D.S. (2008) Synthesis and Characterization of Smooth Ultrananocrystalline Diamond Films via Low Pressure Bias-Enhanced Nucleation and Growth. Applied Physics Letters, 92, Article ID: 133113. http://dx.doi.org/10.1063/1.2838303

[39] Stoner, B.R., Ma, G.H.M., Wolter, S.D. and Glass, J.T. (1992) Characterization of Bias-Enhanced Nucleation of Diamond on Silicon by Invacuo Surface Analysis and Transmission Electron Microscopy. Physical Review B, 45, 1106711084. http://dx.doi.org/10.1103/PhysRevB.45.11067

[40] Maillard-Schaller, E., Kuttel, O.M., Groning, O., Agostino, R.G., Aebi, P., Schlapbach, L., Wurzinger, P. and Pongratz, P. (1997) Local Heteroepitaxy of Diamond on Silicon (100): A Study of the Interface Structure. Physical Review B, 55, 15895. http://dx.doi.org/10.1103/PhysRevB.55.15895

[41] Lu, P., Gomez, H., Xiao, X., Lukitsch, M., Durham, D., Sachdeve, A., Kumar, A. and Chou, K. (2013) Coating Thickness and Interlayer Effects on CVD-Diamond Film Adhesion to Cobalt-Cemented Tungsten Carbides. Surface \& Coatings Technology, 215, 272-279. http://dx.doi.org/10.1016/j.surfcoat.2012.08.093

[42] Chen, H.C., Liu, K.F., Tai, N.H., Pong, W.F. and Lin, I.N. (2010) On the Mechanism of Enhancing the Nucleation Behaviour of UNCD Films by Mo-Coating. Diamond \& Related Materials, 19, 134-137. http://dx.doi.org/10.1016/j.diamond.2009.11.020

[43] Buijnsters, J.G., Vázquez, L., Galindo, R.E. and Meulen, J.J. (2010) Molybdenum Interlayers for Nucleation Enhancement in Diamond CVD Growth. Journal of Nanoscience and Nanotechnology, 10, 2885-2891. http://dx.doi.org/10.1166/jnn.2010.1392

[44] Li, Y.S., Tang, Y., Yang, Q., Maley, J., Sammynaiken, R., Regier, T., Xiao, C. and Hirose, A. (2010) Ultrathin W-Al Dual Interlayer Approach to Depositing Smooth and Adherent Nanocrystalline Diamond Films on Stainless Steel. ACS Applied Materials \& Interfaces, 2, 335-338. http://dx.doi.org/10.1021/am9007159

[45] Chen, L.J., Tai, N.H., Lee, C.Y. and Lin, I.N. (2007) Effects of Pretreatment Processes on Improving the Formation of Nanocrystalline Diamond. Journal of Applied Physics, 101, Article ID: 064308.

[46] Sumant, A.V., Auciello, O., Carpick, R.W., Srinivasan, S. and Butler, J.E. (2010) Ultrananocrystalline and Nanocrystalline Diamond Thin Films for MEMS/NEMS Applications. MRS Bulletin, 35, 281-288. http://dx.doi.org/10.1557/mrs2010.550

[47] Remes, Z., Kozak, H., Rezek, B., Ukraintsev, E., Babchenko, O., Kromka, A., Girard, H.A., Arnault, J.C. and Bergonzo, P. (2013) Diamond-Coated ATR Prism for Infrared Absorption Spectroscopy of Surface-Modified Diamond Nanoparticles. Applied Surface Science, 270, 411-417. http://dx.doi.org/10.1016/j.apsusc.2013.01.039

[48] Buijnsters, J.G., Vázquez, L., Dreumel, G.W.J., Meulen, J.J., Enckevort, W.J.P. and Celis, J.P. (2010) Enhancement of the Nucleation of Smooth and Dense Nanocrystalline Diamond Films by Using Molybdenum Seed Layers. Journal of Applied Physics, 108, Article ID: 103514. http://dx.doi.org/10.1063/1.3506525

[49] Rotter, S.Z. and Madaleno, J.C. (2009) Diamond CVD by a Combined Plasma Pretreatment and Seeding Procedure. Chemical Vapor Deposition, 15, 209-216. http://dx.doi.org/10.1002/cvde.200806745

[50] Edelstein, R.S., Gouzman, I., Folman, M., Rotter, S. and Hoffman, A. (1999) Surface Carbon Saturation as a Means of CVD Diamond Nucleation Enhancement. Diamond \& Related Materials, 8, 139-145. http://dx.doi.org/10.1016/S0925-9635(98)00261-1

[51] Gouzman, I., Richter, V., Rotter, S. and Hoffman, A.J. (2000) Study of Chemical Vapor Deposition Diamond Film Evolution from a Nanodiamond Precursor by C13 Isotopic Labeling and Ion Implantation. Journal of Vacuum Science \& Technology A, 18, 2997. http://dx.doi.org/10.1116/1.1319677

[52] Feng, Z., Komvipoulos, K., Brown, I.G. and Bogy, D.B. (1993) Effect of Graphitic Carbon Films on Diamond Nucleation by Microwave-Plasma-Enhanced Chemical-Vapor Deposition. Journal of Applied Physics, 74, 2841. http://dx.doi.org/10.1063/1.354636

[53] Lee, H.J., Jeon, H. and Lee, W.S. (2011) Ultrathin Ultrananocrystalline Diamond Film Synthesis by Direct Current Plasma-Assisted Chemical Vapor Deposition. Journal of Applied Physics, 110, Article ID: 084305. http://dx.doi.org/10.1063/1.3652752

[54] Butler, J.E. and Sumant, A.V. (2008) The CVD of Nanodiamond Materials. Chemical Vapor Deposition, 14, $145-160$. http://dx.doi.org/10.1002/cvde.200700037

[55] Sumant, A.V., Gilbert, P.U.P.A., Grierson, D.S., Konicek, A.R., Abrecht, M., Butler, J.E., Feygelson, T., Rotter, S.S. and Carpick, R.W. (2007) Surface Composition, Bonding, and Morphology in the Nucleation and Growth of UltraThin, High Quality Nanocrystalline Diamond Films. Diamond \& Related Materials, 16, 718-724. http://dx.doi.org/10.1016/j.diamond.2006.12.011 
[56] Philip, J., Hess, P., Feygelson, T., Butler, J.E., Chattopadhyay, S., Chen, K.H. and Chen, L.C. (2003) Elastic, Mechanical, and Thermal Properties of Nanocrystalline Diamond Films. Journal of Applied Physics, 93, 2164-2171. http://dx.doi.org/10.1063/1.1537465

[57] Metcalf, T.H., Liu, X., Houston, B.H., Baldwin, J.W., Butler, J.E. and Feygelson, T. (2005) Low Temperature Internal Friction in Nanocrystalline Diamond Films. Applied Physics Letters, 86, 81910. http://dx.doi.org/10.1063/1.1868065

[58] Sekaric, L., Parpia, J.M., Craighead, H.G., Feygelson, T., Houston, B.H. and Butler, J.E. (2002) Nanomechanical Resonant Structures in Nanocrystalline Diamond. Applied Physics Letters, 81, 4455-4457. http://dx.doi.org/10.1063/1.1526941

[59] Fhaner, M., Zhao, H., Bian, X., Galligan, J.J. and Swain, G.M. (2011) Improvements in the Formation of Boron-Doped Diamond Coatings on Platinum Wires Using the Novel Nucleation Process (NNP). Diamond \& Related Materials, 20, 75-83. http://dx.doi.org/10.1016/j.diamond.2010.11.003

[60] Mallik, A.K., Pal, K.S., Dandapat, N., Guha, B.K., Datta, S. and Basu, D. (2012) Influence of the Microwave Plasma CVD Reactor Parameters on Substrate Thermal Management for Growing Large Area Diamond Coatings inside a 915 MHz and Moderately Low Power Unit. Diamond \& Related Materials, 30, 53-61. http://dx.doi.org/10.1016/j.diamond.2012.10.001

[61] Mallik, A.K., Bysakh, S., Pal, K.S., Dandapat, N., Guha, B.K., Datta, S. and Basu, D. (2013) Large Area Deposition of Polycrystalline Diamond Coatings by Microwave Plasma CVD. Transactions of the Indian Ceramic Society, 72, 225232. http://dx.doi.org/10.1080/0371750X.2013.870768 